\title{
СВЕТОДИОДЫ И СЕМИОХЕМИКИ РАСТИТЕЛЬНОГО ПРОИСХОЖДЕНИЯ — ПЕРСПЕКТИВНЫЕ СРЕДСТВА МОНИТОРИНГА КУКУРУЗНОГО МОТЫЛЬКА
}

\author{
Фролов А.Н., Грушевая И.В., Мильцььн А.А. \\ Всероссийский научно-исследовательский институт защчтты растений, Санкт- \\ Петербург, Россия, entomology@vizr.spb.ru
}

\begin{abstract}
Delta sticky traps fitted with diverse lures were used in trials for attraction of the European corn borer, Ostrinia nubilalis Hbn. adults at the Kuban Experimental Station, Russian Federation in 2020. In terms of captures, 8 lures tested were divided into 3 groups: traps baited with sex pheromones caught the smallest numbers of moths (0.1-0.4 specimen per 1 trap per week), semiochemicals - the average numbers (alone or in combination with a sex pheromone) (7.0-7.2) and UV LEDs - the maximum number (25.6). In contrast to sex pheromones, LEDs and semiochemicals attracted considerable numbers of females $(28.8-46.6 \%)$ besides males.
\end{abstract}

Key words: Ostrinia nubilalis, sticky trap, sex pheromone, semiochemicals, LED

\section{Введение}

Фитосанитарный мониторинг — важнейшая составляющая интегрированных систем защиты растений. Хотя современные средства отлова насекомых чрезвычайно разнообразны (Epsky et al., 2008; Голуб и др., 2012), наиболее популярны ловушки с синтетическими аналогами половых феромонов, неоспоримыми достоинствами которых являются дешевизна, мобильность, легкость установки и избирательность привлекающего действия в отношении целевого объекта мониторинга (Фролов, 2011). Так, для учетов численности одного из наиболее опасных вредителей кукурузы кукурузного мотылька Ostrinia nubilalis Hbn. (Lepidoptera: Crambidae) обычно используют ловушки с синтетическими половыми феромонами (Laurent, Frérot, 2007), хотя появляются сообщения о том, что аттрактивность последних сильно варьирует в зависимости от условий, порой опускаясь до минимальных значений (Грушевая и др., 2015). Кроме того, феромонные ловушки отлавливают лишь самцов, которые имеют худшую прогностическую ценность в сравнении с самками (Witzgall et al., 2010).

К настоящему времени идентифицировано немало соединений растительного происхождения, аттрактивных для имаго кукурузного мотылька, включая яйцекладущих самок, среди которых наиболее известен фенилацетальдегид (Molnár et al., 2015). Недавно обнаружилось, что добавление к нему также выделенного из кукурузы летучего семиохемика 4-метокси-2-фенэтилового спирта повышает уловистость ловушек в 3-5 раз (Tóth et al., 2016). Проведенные в пяти странах Европы испытания этой комбинации семиохемиков под коммерческим названием bisex lure подтвердили этот результат (Tóth et al., 2017). Выполненные нами в 2019 г. пилотные испытания ловушек c bisex lure в Краснодарском крае и Воронежской обл. 
свидетельствуют о высокой эффективности этимх семиохемиков для мониторинга кукурузного мотылька (Фролов и др., 2020).

Световые ловушки издавна используются в качестве средства мониторинга вредных насекомых (Терсков, Коломиец, 1966). Как и семиохемики, свет, в отличие от полового феромона, способен привлекать особей обоих полов (Nowinszky, Puskás, 2015). До недавнего времени широкому применению световых ловушек препятствовали их громоздкость и высокий расход энергии, однако благодаря появлению светодиодной техники указанные недостатки оказались преодоленными. Примеров использования светодиодных ловушек для мониторинга кукурузного мотылька пока немного, однако их перспективность подтверждена результатами успешно проведенных нами испытаний в трех пунктах Краснодарского края (Грушевая и др., 2019).

Цель настоящей работы - провести сравнительную оценку эффективности отлова имаго кукурузного мотылька снабженными светодиодами и семиохемиками клеевыми ловушками Дельта в сравнении с синтетическими половыми феромонами.

\section{Материал и методы}

Исследования проводили в 2020 г. на посеве кукурузы Кубанской опытной станции ВИР (филиал Всероссийского института генетических ресурсов растений им. Н.И. Вавилова), расположенной на территории пос. Ботаника Гулькевичского р-на $\left(45^{\circ} 18^{\circ}\right.$ с.ш. и $40^{\circ} 52^{\circ}$ в.д.). Для испытаний использовали два типа клеевых ловушек Дельта - стандартные картонные производства АО «Щелково Агрохим» (г. Москва) и пластиковые, изготовленные в ВИЗР (рис. 1). В каждую картонную ловушку помещали по одной из указанных ниже приманок: 1) резиновый диспенсер с синтетическим половым феромоном (по 100 мкг/диспенсер), привлекающий самцов кукурузного мотылька расы Z (феромон состава 3:97 E/Z 11-14:OAc), E (99:1 E/Z 11-14:OAc) или ZE (65:35 E/Z 11-14:ОАc) (всё производства АО «Щелково Агрохим», далее обозначены как варианты испытаний Z1, E1, ZE1); 2) резиновый диспенсер с синтетическим половым феромоном (по 100 мкг/диспенсер), активным в отношении самцов Z расы насекомого (производство ООО «Феромон», г. Москва, обозначен как вариант Z2); 3) коммерческую бисексуальную приманку (комбинация фенилацетальдегида и 4метокси-2-фенэтилового спирта, по 100 мг каждого) в полиэтиленовом диспенсере производства Института защиты растений, Будапешт, Венгрия (вариант СX1); 4) комбинацию фольгапленовых диспенсеров, содержащих семиохемики 4-метокси-2фенэтиловый спирт и фенилацетальдегид (по 100 мг каждого) производства АО «Щелково Агрохим» (вариант CX2); 5) комбинацию фольгапленовых диспенсеров с указанными в варианте CX2 семиохемиками и синтетическим половым феромоном, специфичным для Z-расы вредителя, производство АО «Щелково Агрохим» (вариант CXZ2). Пластиковые ловушки снабжали съемной кассетой с двумя светодиодами мощностью 3 Вт, испускающими свет длиной волны 365-370 нМ в противоположные стороны друг от друга вдоль корпуса ловушки. Источником питания служили 6 аккумуляторов 1,2 В, 2200 мА/час, а управляющим устройством - микроконтроллер Attiny 13A, который позволял автоматически перепрограммировать порог срабатывания ловушки (вариант испытаний СВ) (Мильцын и др., 2020). Таким образом, всего в испытаниях использовали 8 вариантов приманок, обозначенных как Z1, E1, ZE1, Z2, $\mathrm{CX} 1, \mathrm{CX} 2, \mathrm{CXZ2}$ и СВ. Ловушки размещали в 6 рендомизированных блоках перед началом лёта имаго кукурузного мотылька первого поколения на участке площадью 23 га, занятым посевом кукурузы гибрида Командос (KWS). 


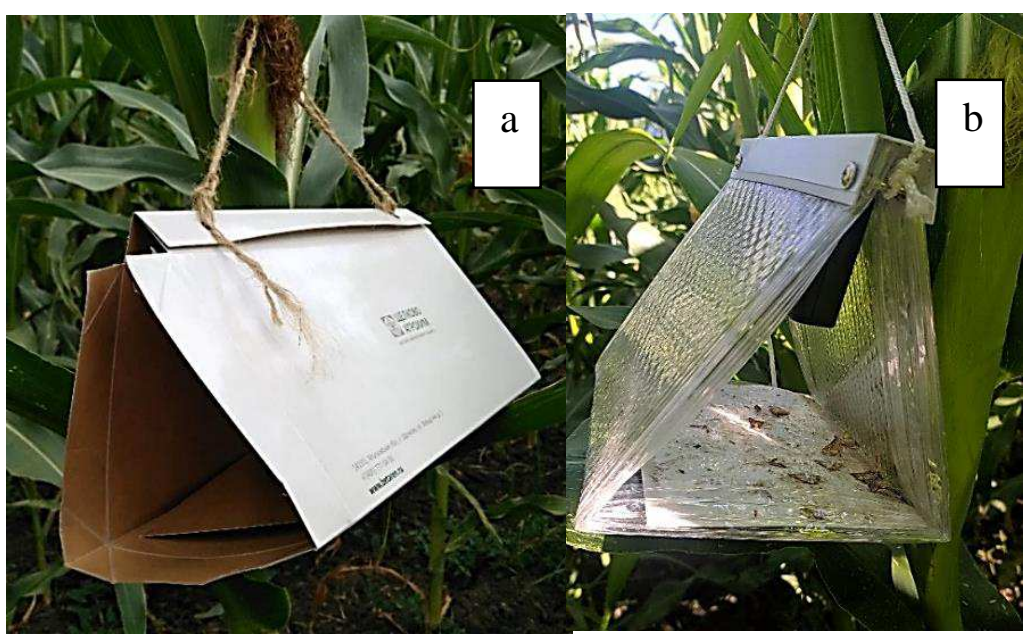

Рисунок 1. Ловушки

Дельта, использованные

в испытаниях

аттрактивности

приманок для имаго

кукурузного мотылька:

картонная ловушка

производства АО

«Щелково Агрохим» (а)

и пластиковая

светодиодная ловушка, изготовленная в ВИЗР

(b).

Расстояние между ловушками внутри блока составляло 8-10 м, а между блоками - не менее 30 м. Осмотр ловушек и подсчет отловленных имаго проводили каждые 3-4 дня, начиная с момента попадания в ловушку первой бабочки (до этого момента ловушки осматривали ежедневно). Отловленных в ловушки насекомых удаляли, вкладыш заменяли на свежий в случае его сильного загрязнения. Статистическую обработку данных проводили с помощью дисперсионного анализа при выравнивании дисперсий путем логарифмирования и $\varphi$-преобразования Фишера, а значимость различий оценивали с использованием критерия Дункана.

\section{Результаты и обсуждение}

Результаты отлова имаго кукурузного мотылька ловушками с различными приманками представлены в таблице 1. Дисперсионный анализ доказал высокодостоверный эффект фактора приманки $\left(\mathrm{p}_{\alpha} \leq 0.001\right)$, составивший $59.0 \%$ от общей дисперсии. Данные таблицы 1 наглядно свидетельствуют о том, что по аттрактивности приманки разделились на 3 статистически достоверно различающиеся между собой группы: меньше всего имаго вредителя отлавливали ловушки с половыми феромонами (0.12 - 0.36 особей на 1 ловушку за неделю), тогда как ловушки с семиохемиками (включая их комбинацию с половым феромоном) отлавливали бабочек почти в 20 раз интенсивнее (7.03 - 7.18), а со светодиодами - более чем в 70 раз (25.64 особей на 1 ловушку за неделю).

Таблица 1. Плотности имаго кукурузного мотылька, отловленных в клеевые ловушки Дельта с разными приманками в расчете на 1 ловушку за 1 неделю лёта насекомых (пос. Ботаника Краснодарского края, 2020)

\begin{tabular}{|c|c|c|c|c|c|c|c|}
\hline Z1*) & E1 & ZE1 & Z2 & CX1 & CX2 & CXZ2 & CB \\
\hline $0.36 \pm 0.18$ & $0.18 \pm$ & $0.12 \pm$ & $0.30 \pm$ & $7.03 \pm$ & $7.03 \pm$ & $7.18 \pm$ & $25.64 \pm$ \\
$\mathrm{a} * *)$ & $0.07 \mathrm{a}$ & $0.06 \mathrm{a}$ & $0.08 \mathrm{a}$ & $0.58 \mathrm{~b}$ & $0.77 \mathrm{~b}$ & $0.80 \mathrm{~b}$ & $1.58 \mathrm{c}$ \\
\hline
\end{tabular}

Примечения: *) Расшифровку приманок см. в $\quad$ разделе **) среднее \pm стандартная ошибка средней $(\overline{\mathrm{X}} \pm \mathrm{SE})$; разными буквенными символами снабжены средние, достоверно различающиеся по критерию Дункана при $\mathrm{p}_{\alpha} \leq 0.05$

В отличие от половых феромонов, как семиохемики, так и светодиоды привлекали помимо самцов немалые количества самок. При этом хотя доля последних в отловах оказалась достоверно выше в ловушках с семиохемиками, в абсолютном 
исчислении в расчете на 1 ловушку светодиодами было привлечено особей женского пола более, чем в 2 раза больше (табл. 2).

Таблица 2. Отловы самок кукурузного мотылька клеевыми ловушками Дельта в расчете на 1 ловушку за 1 неделю лёта насекомых (пос. Ботаника Краснодарского края, 2020)

\begin{tabular}{|c|c|c|c|c|}
\hline Приманки & CX1 *) & CX2 & CXZ2 & CВ \\
\hline Кол-во самок & $17.67 \pm 1.60 \mathrm{a} * *)$ & $18.17 \pm 2.33 \mathrm{a}$ & $16.83 \pm 1.99 \mathrm{a}$ & $41.00 \pm 4.46 \mathrm{~b}$ \\
\hline $\begin{array}{c}\text { Доля отловленных } \\
\text { самок (\%) }\end{array}$ & $46.57 \pm 4.28 \mathrm{~b} * *)$ & $46.60 \pm 2.39 \mathrm{~b}$ & $42.62 \pm 1.78 \mathrm{~b}$ & $28.78 \pm 1.58 \mathrm{a}$ \\
\hline
\end{tabular}

См. примечания к табл. 1.

\section{Выводы}

Представленные результаты испытаний, несмотря на одногодичность, убедительно свидетельствуют о перспективности использования ловушек, снабженных как светодиодами, так и семиохемиками растительного происхождения, для мониторинга кукурузного мотылька. Очевидным преимуществом и тех, и других является то обстоятельство, что, в отличие от половых феромонов, они привлекают немало самок, чья прогностическая ценность существенно выше, чем таковая самцов.

Светодиоды обнаружили максимальный выигрыш по уловистости имаго кукурузного мотылька в сравнении со всеми остальными испытанными приманами в клеевых ловушках, включая семиохемики. При этом добавление полового феромона к последним не обеспечивало синергистского эффекта в отношении привлекательности для насекомого. Впрочем, хотя ловушки со светодиодами и отлавливали рекордные количества особей вредителя, ловушки с семиохемиками обладают определенными преимуществами - они удобнее в обслуживании, т.к. не требуют периодической замены источников электропитания. Кроме того, их производство обходится дешевле, чем светодиодных ловушек, что, впрочем, отчасти компенсируется тем обстоятельством, что конструкция последних предусматривает возможность многолетнего использования.

\section{Благодарности}

Авторы благодарят С.В.Стулова (АО «Щелково Агрохим»), О.Г.Скорынина (OOO «Феромон») и Miklós Tóth (Plant Protection Institute, Hungarian Academy of Sciences) за предоставленный материал, а также Ю.А.Елацкова (Кубанская опытная станция ВИР) за возможность проведения НИР на посевах кукурузы. Работа выполнена при частичном финансировании РФФИ (грант № 19-016-00128).

\section{Библиография}

Голуб В.Б., Цуриков М.Н., Прокин А.А. (2012). Коллекции насекомых: сбор, обработка и хранение материала. Москва: Товарищество научных изданий КМК. 339 с.

Грушевая И.В., Конончук А.Г., Малыш С.М., Мильцын А.А., Фролов А.Н. (2019). Светодиодная ловушка для мониторинга кукурузного мотылька Ostrinia nubilalis: испытания в Краснодарском крае. Вестник защиты растений, 4: 49-54.

Грушевая И.В., Фролов А.Н., Рябчинская Т.А., Трепашко Л.И., Быковская А.В. (2015). Феромониторинг Ostrinia nubilalis Hbn.: проблема с аттрактивностью известных композиций. Образование, наука и производство, 3(12): 107-110.

Мильцын А.А., Грушевая И.В., Конончук А.Г., Малыш Ю.М., Токарев Ю.С., Фролов А.Н. (2020). Световая ловушка для мониторинга насекомых. Патент на полезную модель RU 195732 U1, 04.02.2020. Заявка № 2019131861 от 09.10.2019. 
Фролов А.Н. (2011). Современные направления совершенствования прогнозов и мониторинга. Защита и карантин растений, 4: 15-20.

Epsky N.D., Morrill W.L., Mankin R.W. (2008). Traps for capturing insects. In: J.L.Capinera (ed.). Encyclopedia of Entomology, 2nd Edition. Springer Science \& Business Media, Heidelberg, p. 3887-3901.

Laurent P., Frérot B. (2007). Monitoring of European corn borer with pheromonebaited traps: review of trapping system basics and remaining problems. Journal of Economic Entomology, 100(6): 1797-1807.

Molnár B.P., Tóth Z., Fejes-Tóth A., Dekker T., Kárpáti Z. (2015). Electrophysiologically-active maize volatiles attract gravid female European corn borer, Ostrinia nubilalis. Journal of Chemical Ecology, 41(11): 997-1005.

Nowinszky L., Puskás J. (2015). Sex ratio analysis of some Macrolepidoptera species collected by Hungarian forestry light traps. Acta Silvatica et Lignaria Hungarica, 11(2): 99110 .

Tóth M., Szarukán I., Nagy A., Ábri T., Katona V., Körösi S., Nagy T., Szarvas Á., Koczor S. (2016). An improved female-targeted semiochemical lure for the European corn borer Ostrinia nubilalis Hbn. Acta Phytopathologica et Entomologica Hungarica, 51(2): 247254.

Tóth M., Szarukán I., Nagy A., Furlan L., Benvegnù I., Rak Cizej M., Ábri T., Kéki T., Körösi S., Pogonyi A., Toshova T., Velchev D., Atanasova D., Kurtulus A., Kaydan B.M., Signori A. (2017). European corn borer (Ostrinia nubilalis Hbn., Lepidoptera: Crambidae): comparing the performance of a new bisexual lure with that of synthetic sex pheromone in five countries. Pest Management Science, 73(12): 2504-2508.

Witzgall P., Kirsch P., Cork A. (2010). Sex pheromones and their impact on pest management. Journal of Chemical Ecology, 36(1): 80-100. 